\title{
Influência de fatores climáticos na dispersão aérea de Phakopsora euvitis Y. Ono na cultura da videira.
}

\author{
Diógenes da Cruz Batista@ 1, Marcos Brandão Braga๑ 2 , José Barbosa dos Anjos@ 1; \\ Maria Angélica Guimarães Barbosa ${ }^{1}$
}

${ }^{1}$ Embrapa Semiárido, Rodovia BR-428, Km 152, Zona Rural - CP 23, CEP 56302-970 Petrolina, PE, Brasil. ²Embrapa Hortaliças, Rodovia BR060, Km 09 (Brasília/Anápolis), Fazenda Tamanduá, CP218, CEP 70275-970 Brasília, DF, Brasil.

Autor para correspondência: Diógenes da Cruz Batista (diogenes.batista@embrapa.br)

Data de chegada: 19/02/2019. Aceito para publicação em: 01/06/2020.

$10.1590 / 0100-5405 / 220166$

\section{RESUMO}

Batista, D.C.; Braga, M.B.; Anjos, J.B.; Barbosa, M.A.G. Influência de fatores climáticos na dispersão aérea de Phakopsora euvitis Y. Ono na cultura da videira. Summa Phytopathologica, v.46, n.3, p.221-227, 2020.

A ferrugem da videira, uma das doenças mais importantes de Vitis spp., é manejada no Brasil seguindo um programa de calendário de pulverização de fungicidas. Apesar da utilização de fungicidas, as perdas de produção e qualidade das uvas devido à ferrugem da videira são elevadas. A doença causa queda de folhas, tamanho e cor desigual de bagas e perda de vigor das plantas para a próxima safra. $\mathrm{O}$ objetivo deste estudo foi investigar a relação entre a dispersão de urediniósporos presente no ar e os parâmetros meteorológicos, para fins de manejo da doença. Para tanto, monitorou-se vinhedos com a cultivar Syrah, suscetível a ferrugem da videira, para determinar a dinâmica de dispersão aérea de Phakopsora euvitis. As armadilhas tipo cata-vento foram mantidas a $0,5 \mathrm{~m}$ acima do dossel da videira e as amostras coletadas a cada 24 h, com troca de lâminas as $09 \mathrm{~h} 00 \mathrm{~min}$. As médias horárias da temperatura do ar, velocidade do vento, umidade relativa e precipitação foram também registradas. Modelo de regressão logística foi desenvolvido para estimar a probabilidade de dispersão de urediniósporos. As maiores concentrações de urediniósporos foram observadas entre abril e agosto, enquanto nos demais meses a concentração foi baixa ou zero. O modelo de regressão da concentração de urediniósporos disperso no ar em relação aos parâmetros climáticos foi descrito por logit (y) $=15,6668-0,6333$ (temperatura) $+0,4291$ (velocidade do vento), e o limiar de decisão de valor 0,47 foi determinado para fins de previsão.

Palavras-chave: Vitis, ferrugem da videira, risco, modelo logístico.

\section{ABSTRACT}

Batista, D.C.; Braga, M.B.; Anjos, J.B.; Barbosa, M.A.G. Influence of climate factors on Phakopsora euvitis Y. Ono airborne dispersal in grapevine crop. Summa Phytopathologica, v.46, n.3, p.221-227, 2020.

Grape rust, one of the most important diseases of Vitis spp., is managed in Brazil according to a calendar-based fungicide spray program. Despite the use of fungicides, the crop and the quality of grapes have shown significant losses due to rust. This disease causes leaf fall, unequal size and color of berries and loss in plant vigor in the following harvest. The aim of this study was to investigate the relationship between airborne urediniospore dispersal and weather parameters to improve the management of this disease. Thus, vineyards of the cultivar 'Syrah', susceptible to grape rust, were monitored to determine Phakopsora euvitis airborne dispersal dynamic. Wind vane spore traps were maintained at $0.5 \mathrm{~m}$ above the grapevine canopy and samples were collected every $24 \mathrm{~h}$, while slides were changed at 9:00 a.m. A logistic regression model was developed to estimate the urediniospore dispersal probability. Higher urediniospore concentrations were observed between April and August, while in the remaining months the concentration was low or zero. The regression model of the airborne urediniospore concentration relative to the weather parameters was described as logit $(\mathrm{Y})=15.6668-0.6333$ (temperature) + 0.4291 (wind speed), and a decision threshold of 0.47 was determined for predictive purposes.

Keywords: Vitis, grape rust, risk, logistic model.

A vitivinicultura tem uma importante participação na atividade agrícola do Brasil, com uma área plantada de 78.028 ha. No sul do país estão pouco mais de $70 \%$ dos parreirais, principalmente no Rio Grande do Sul. Pernambuco (7.092 ha) e Bahia (1.919 ha) correspondem por praticamente toda produção do nordeste $(9.172$ ha), distribuída em cultivos no semiárido do Vale do São Francisco (14). Entretanto, doenças provocam danos e perdas de produção em videiras, e entre elas a ferrugem, causada por Phakopsora euvitis Y. Ono, é considerada uma doença foliar severa em final de ciclo, ocasionando desfolha precoce (9), maturação desuniforme e má qualidade de bagas, além de comprometer a produção do ciclo seguinte decorrente da redução do vigor das plantas. Os sintomas são pústulas amareladas na superfície inferior da folha e necrose do tecido no lado oposto às pústulas (23). Descrita na Ásia, Américas e Oceania (9), foi no Paraná e São Paulo os primeiros registros no Brasil, disseminando, posteriormente, para outros estados $(6,23)$. Em Pernambuco, as videiras têm apresentado intensidade variável da doença em função da variedade $(2,13)$ e das condições ambientais que influenciam na atividade do patógeno (3). A temperatura, luminosidade, umidade relativa e molhamento foliar são os parâmetros ambientais que normalmente interferem na intensidade da ferrugem da videira. E apesar da doença se desenvolver numa faixa ampla de temperatura, é entre $24^{\circ} \mathrm{C}$ e $25^{\circ} \mathrm{C}$ considerado ótimo (11).

A principal via de disseminação da ferrugem da videira a longa distância é por material infectado. Entretanto, epidemias são iniciadas por urediniósporos liberados por ação do vento a partir de folhas doentes em plantios próximos $(5,6)$. Apenas a fase uredinial e telial com a formação de urediniósporos e teliósporos, respectivamente, foram observados no Brasil. O ciclo completo do patógeno é restrito ao 
continente asiático onde se encontra o hospedeiro alternativo Meliosma myriantha. Assim, conforme Bayer \& Costa (6), a fase uredinial é a responsável pelas epidemias no Brasil.

A forma de dispersão do patógeno influencia no curso temporal e espacial de epidemias, sendo a dispersão aérea importante na disseminação de doenças que dependem de vários ciclos de infecções (4). As ferrugens são doenças do tipo policíclicas que se iniciam a partir de inóculo primário e se desenvolvem por inóculos secundários (6). A dispersão de agentes patogênicos é fundamental para o desenvolvimento de epidemias em plantas (19), e estudos sobre dispersão de patógenos contribuem para compreensão e desenvolvimento de estratégias de manejo de doenças. Para tanto, esforços têm sido feitos na obtenção de informações de campos a fim de orientar táticas de manejo e validar prognósticos teóricos de dispersão e doença $(19,24)$. Contudo, apesar da importância da ferrugem da videira, existem poucos estudos, em condições naturais, quanto aos aspectos epidemiológicos da doença no Brasil, inclusive, na região semiárida do país.

O objetivo do trabalho foi estudar a influência de elementos climáticos na dinâmica temporal de urediniósporos de $P$. euvitis em plantios de videira a fim de subsidiar decisões de manejo da ferrugem da videira.

\section{MATERIAL E MÉTODOS}

A dispersão de $P$. euvitis foi quantificada em duas áreas de videira, cv. Syrah, enxertada sobre o porta-enxerto 1103 Paulsen, na Estação Experimental da Embrapa semiárido no Perímetro Irrigado de Bebedouro-PE (latitude $09^{\circ} 09^{\prime} \mathrm{S}$, longitude $40^{\circ} 22^{\prime} \mathrm{W}$ e altitude $365 \mathrm{~m}$ ). O monitoramento foi realizado com armadilhas tipo catavento, instaladas a 0,5 metros de altura acima do dossel da videira. A área de coleta de cada armadilha foi uma lâmina de vidro, com 10 $\mathrm{cm}$ de comprimento e $2 \mathrm{~cm}$ de largura, posicionada numa inclinação de $45^{\circ}$ e coberta com uma camada de graxa de silicone. O período de amostragem foi de 24 horas e as lâminas foram trocadas diariamente às 9:00 horas. As lâminas eram retiradas e acondicionadas em laminários de madeira, próprios para transporte até o laboratório, onde era realizada observação microscópica, contagem do número de urediniósporos aderidos às lâminas de vidro e determinação da concentração diária de conídios $/ \mathrm{cm}^{2}$. Os dados climáticos foram registrados e armazenados em coletor automático de dados (Campbell Scientific CR10X).

Estudou-se por regressão logística a probabilidade de ocorrerem eventos de números de urediniósporos maior que $1 \%$ da concentração máxima observada $(\mathrm{CMO})$ em relação às variáveis ambientais. A variável resposta foi construída baseada no número de urediniósporos (S) e adotada uma escala binária classificada conforme o número de urediniósporos capturados/dia: $\mathrm{Y}=0$ se $\mathrm{S} \leq 1 \%$ da $\mathrm{CMO}$ e $\mathrm{Y}=1$ se $\mathrm{S}>$ $1 \%$ da CMO. A variável S foi indicadora de aumento da concentração de urediniósporos no ar. A probabilidade $\mathrm{P}(\mathrm{Y}=1)$ foi modelada como uma função das variáveis: temperatura, umidade relativa, velocidade do vento e precipitação pluviométrica. $\mathrm{O}$ modelo logístico utilizado foi: $\mathrm{P}(\mathrm{y})=\left[1+\exp \left(-\alpha-\beta_{1} \mathrm{X}_{1}-\ldots-\beta_{\mathrm{n}} \mathrm{X}_{\mathrm{n}}\right)\right]^{-1}$, onde $\mathrm{P}(\mathrm{y})$ é a probabilidade do evento $\mathrm{y}, \alpha$ é o intercepto, $\beta$ 's são os coeficientes da regressão e $X$ 's são as variáveis independentes. No modelo, a chance de o evento ocorrer (número de urediniósporos maior que 1\% da CMO) dada pela expressão $\mathrm{p} /(1-\mathrm{p})$, foi modelada pela função linear de resposta: $\ln [\mathrm{p} /$ $(1-p)]=\alpha+b_{1} T+b_{2} P+b_{3} U+b_{4} V+b_{5} T P U V$, onde a expressão [p/(1p)], chance de um evento, é definida como a probabilidade do evento ocorrer (p) em relação à probabilidade, sob as mesmas condições, do evento não ocorrer (1-p), $\alpha$ é o intercepto, $b_{i}$ 's são as estimativas dos parâmetros $\beta$ 's, T é a temperatura média do ar, P é a precipitação total, $\mathrm{U}$ é a umidade relativa média do ar e $\mathrm{V}$ é a velocidade média do vento. A regressão logística permite estimar, também, a razão de chances (RC), que é uma medida da quantidade relativa pela qual a chance de um dado resultado aumenta $(\mathrm{RC}>1,0)$ ou diminui $(\mathrm{RC}<1,0)$, quando o valor da variável preditora é aumentado em 1,0 unidade $(15,16)$. Enfoques semelhantes foram empregados para determinar riscos para outras doenças de plantas $(15,18,21)$.

As análises foram realizadas com o programa SAS® e a escolha do melhor modelo com auxílio da opção "stepwise" do procedimento PROC LOGISTIC. Dados de monitoramento de urediniósporos nos anos de 2009, 2010 e entre 2013 e 2014 foram utilizados para avaliar o modelo selecionado.

\section{RESULTADOS E DISCUSSÃO}

A dinâmica temporal de $P$. euvitis apresentou um padrão de período de alta e baixa dispersão influenciada pelas condições meteorológicas. Maior concentração de urediniósporos foi observada nos meses de abril, maio, junho, julho e agosto. Entre setembro e março a dispersão foi baixa ou zero, enquanto picos maiores ocorreram principalmente nos meses de abril e maio (Figuras 1A e 1B). Como nas proximidades e na área de amostragem houve sempre a presença do hospedeiro, os fatores que contribuíram para o desenvolvimento da doença foram chuvas, alta umidade relativa e temperaturas mais amenas (Figura 1C).

Os meses que registraram menores valores de temperatura média mensal foram abril $\left(24,5^{\circ} \mathrm{C}\right)$, maio $\left(24,9^{\circ} \mathrm{C}\right)$, junho $\left(22,87^{\circ} \mathrm{C}\right)$, julho $\left(22,61^{\circ} \mathrm{C}\right)$ e agosto $\left(23,66^{\circ} \mathrm{C}\right)$. Enquanto as médias mensais de temperatura do ar foram altas para os meses de outubro $\left(27,74^{\circ} \mathrm{C}\right)$, novembro $\left(28,2^{\circ} \mathrm{C}\right)$, dezembro $\left(26,3^{\circ} \mathrm{C}\right)$, janeiro $\left(26,4^{\circ} \mathrm{C}\right)$, fevereiro $\left(27^{\circ} \mathrm{C}\right)$ e março $\left(26,3^{\circ} \mathrm{C}\right)$. Esses dados corroboram com as informações agrometeorológicas disponíveis na Embrapa semiárido entre 1963 e 2009 (22), onde a temperatura tende a aumentar a partir de agosto (> $\left.25^{\circ} \mathrm{C}\right)$, com pico máximo em novembro $\left(28^{\circ} \mathrm{C}\right)$ e queda em maio $(<$ $25^{\circ} \mathrm{C}$ ). Os registros de precipitação e umidade relativa foram, também, semelhantes aos dados históricos.

O modelo logístico ajustado (Tabela 1) para estimar a probabilidade de dispersão maior que $1 \%$ da $\mathrm{CMO}$, isto é, de $\mathrm{Y}=1$ foi: $\mathrm{P}(\mathrm{y})=[1+$ $\left.\mathrm{e}^{-(15,6668-0,633 \mathrm{~T}+0,4291 \mathrm{~V})}\right]^{-1}$. Nesse modelo, a probabilidade de ter mais de $1 \%$ da CMO de urediniósporos no ar foi negativamente relacionada à temperatura média diária do ar $(\mathrm{P}<0,0001)$ e positivamente relacionada à velocidade média diária do vento $(\mathrm{P}<0,0205)$. Deste modo, quanto mais alta a temperatura e mais baixa a velocidade do vento, menor será a probabilidade da dispersão de urediniósporos alcançar níveis superiores a $1 \%$ da CMO (Figura 2A). Importantes para o processo infeccioso, as variáveis P e U não foram significativas no modelo para explicar a dispersão de $P$. euvitis. Possivelmente devido às chuvas removerem os urediniósporos para o solo e o orvalho reter o inóculo na superfície foliar.

$\mathrm{O}$ ajuste do modelo foi considerado adequado, e os coeficientes que medem a associação entre as probabilidades preditas e observadas (Tabela 1) apresentaram alto valor de porcentagem de concordância $(80,1 \%)$ e baixo de discordância $(19,8 \%)$. O valor do coeficiente que mede a acurácia do modelo também foi alto $(\mathrm{c}=0,801)$.

A razão de chances $(\mathrm{RC})$ determinada no modelo para os parâmetros $\mathrm{T}$ e $\mathrm{V}$ foram respectivamente, 0,531 e 1,536. Assim baseado no ajuste do presente modelo, espera-se que para cada acréscimo em $1,0{ }^{\circ} \mathrm{C}$ na 


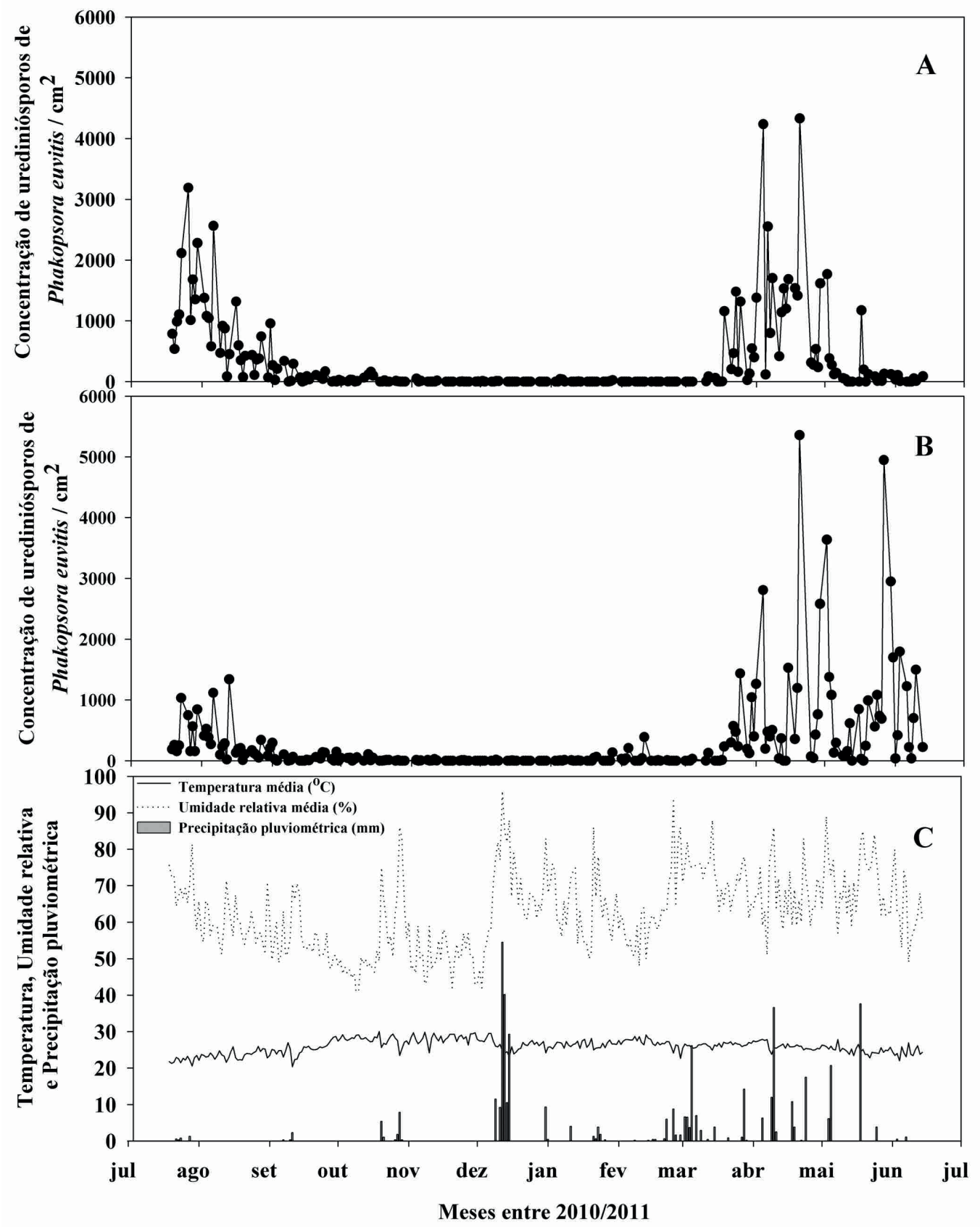

Figura 1. (A e B) Dados da concentração de urediniósporos de Phakopsora euvitis dispersos no ar e capturados por duas armadilhas tipo catavento. (C) Registros das variáveis climáticas entre meses de 2010 e 2011.

Tabela 1. Coeficientes estimados para prognóstico da dispersão aérea de urediniósporos de Phakopsora euvitis obtidos para o modelo regressão logística binomial

\begin{tabular}{ccccccc}
\hline Parâmetros & Estimador & Desvio padrão & Wald $\chi^{2}$ & $\operatorname{Pr}>\chi^{2}$ & Razão de Chances (RC) & 95\% IC (RC) \\
\hline intercepto & 15,6668 & 2,7686 & 32,0218 & $<0,0001$ & & \\
T & $-0,6333$ & 0,1040 & 37,0533 & $<0,0001$ & 0,531 & 1,536 \\
V & 0,4291 & 0,1852 & 5,3688 & $<0,0205$ & & \\
c & 0,801 & & & & & \\
\hline
\end{tabular}

T: Temperatura média diária do ar. V: Velocidade média diária do vento. IC: Intervalo de confiança. 


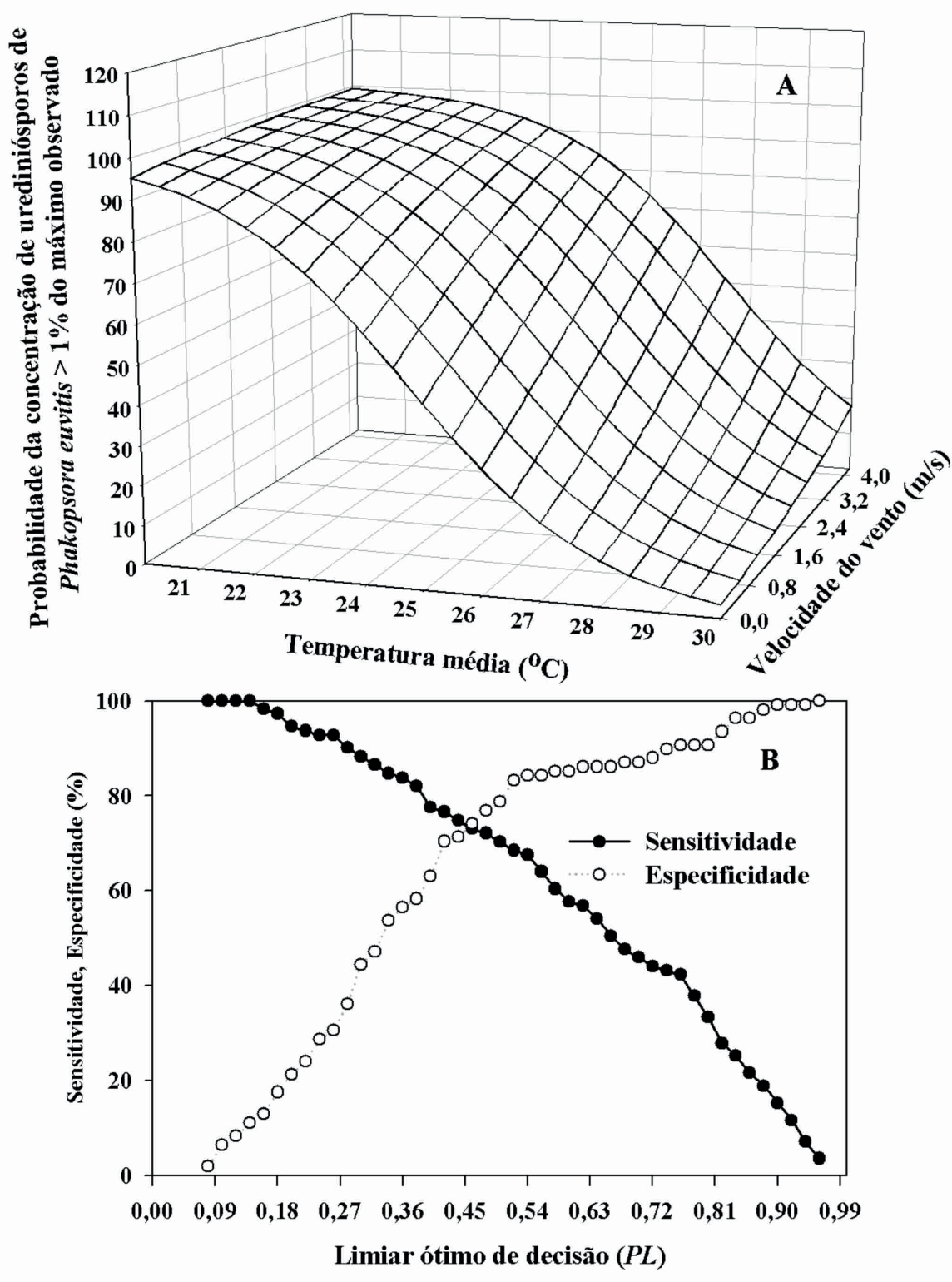

Figura 2. A) Valores de probabilidade estimados (\%) com o modelo logístico $\mathrm{P}(\mathrm{y})=\left[1+\mathrm{e}^{-(15,6668-0,6333 \mathrm{~T}+0,4291 \mathrm{~V})}\right]^{-1}$ em função da temperatura média diária do ar $\left(\mathrm{T}\right.$ em $\left.{ }^{\circ} \mathrm{C}\right)$ e velocidade média diária do vento $(\mathrm{V}$ em $\mathrm{m} / \mathrm{s})$. B) Sensitividade e especificidade em função do nível de probabilidade estimado pelo modelo.

temperatura do ar haja uma redução aproximada de $47 \%$ (conforme cálculo: $\left.\mathrm{e}^{-0,6333}-1=-0,469\right)$ na chance de detectar mais de $1 \%$ da CMO de urediniósporos $(\mathrm{Y}=1)$, ajustado para outra variável no modelo. Por outro lado, para cada acréscimo em $1,0 \mathrm{~m} / \mathrm{s}$ na velocidade do vento a chance de detectar mais de $1 \%$ da CMO de urediniósporos aumenta em aproximadamente $53,5 \%\left(\mathrm{e}^{0,4291}-1=0,535\right)$, também ajustado para outra variável no modelo. Essas informações obtidas com o modelo refletem e corroboram os resultados de Angelotti et al. (3) em que temperaturas altas são prejudiciais ao patógeno. No entanto, a ação do vento é fator importante na dispersão aérea de urediniósporos (6). Semelhante, as menores concentrações de urediniósporos no ar ocorreram nos meses mais quentes (setembro a dezembro; janeiro a março), conforme os dados meteorológicos registrados no presente estudo.

O modelo logístico ajustado, estima a probabilidade ' $p$ ' de ocorrer o evento. Entretanto, a utilização prática do modelo requer o estabelecimento de um limiar de decisão, isto é, um valor $P L$ tal que se ' $p$ ' $\geq P L$ determinado risco ocorra (dispersão de inóculo) e uma ação possa ser adotada (aplicação de fungicida ou produtos alternativos). $\mathrm{O}$ valor $P L$, ponto de corte no gráfico, foi definido como aquele que combinou altas sensitividade (probabilidade do modelo estimar a ocorrência do evento, dado que o evento ocorre) e especificidade (probabilidade do modelo estimar a não ocorrência do evento, dado que o evento não ocorre). Assim, baseado na sensitividade e especificidade o melhor limiar de decisão calculado foi o valor $P L=0,47$ ou $47 \%$ (Figura 2B). A interpretação deste valor para fins de quantificação de risco significa que adoção de medidas de controle deve ser realizada quando a probabilidade atingir este nível, pois neste ponto há a combinação de alta sensitividade e alta especificidade. A proteção das plantas pode ser obtida com o uso de produtos eficientes registrados no Brasil para a 

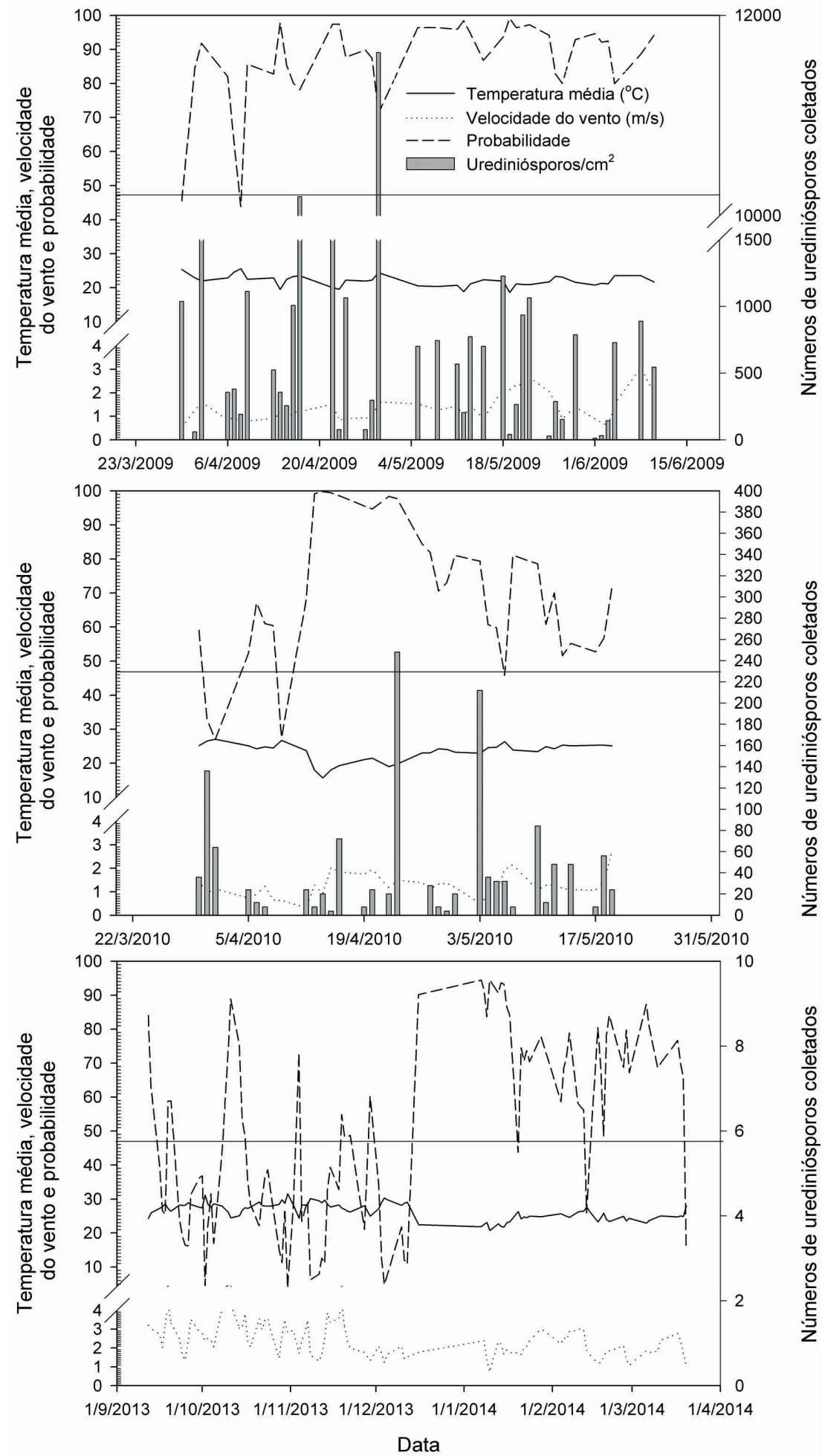

Figura 3. Registros das variáveis climáticas (temperatura média e velocidade do vento média), probabilidade estimada pelo modelo em função daquelas variáveis e concentração de urediniósporos/ $\mathrm{cm}^{2}$ de Phakopsora euvitis disperso no ar, em 2009, 2010 e entre 2013 a 2014 . Linha horizontal localizada no eixo de valor $47 \%$ indica o limiar de decisão, $P L$, do modelo.

ferrugem da videira, a exemplo do tebuconazol, tetraconazol, metiram + piraclostrobina.

Para produtores avessos ao risco, a utilização de um limiar de risco que combina alta sensitividade e baixa especificidade, implica no risco em realizar desnecessariamente uma determinada ação para o controle da doença, pois nesta condição a ocorrência de falsos positivos é alta. Inversamente, quando o limiar de risco combina baixa sensitividade e alta especificidade, a possibilidade de tomar uma decisão errada pela 
não realização da ação de controle da doença demanda alto risco para a cultura, pois neste caso a ocorrência de falsos negativos também é alta. Nessa linha de raciocínio, Gent et al. (10) destacam que sistemas de apoio a tomada de decisão pode ajudar a informar sobre o risco de doença e, assim, ajudar na precisão quanto a eventos críticos e que a subutilização de alguns sistemas de apoio à decisão é provavelmente devido a restrição técnica e abordagem inadequada durante as fases de desenvolvimento e implementação dos mesmos. Entretanto, segundo os autores a incorporação de probabilidades subjetivas em recomendações de manejo pode ser um meio para reduzir a incerteza do produtor e melhorar a confiança desses sistemas pela percepção do risco. Um modelo atraente e que tem auxiliado na tomada de decisão é o desenvolvido para prever o risco de fusariose do trigo (Gibberella zeae) e disponível, via Website, para consulta (http:// www.wheatscab.psu.edu). Modelos similares têm sido propostos para outros patossistemas $(12,8,20)$.

Avaliação do modelo confrontando os dados de números de urediniósporos capturados acima de 53 urediniósporos $/ \mathrm{cm}^{2}(1 \%$ da $\mathrm{CMO}$ ) com o valor $P L=47 \%$ (Figura 3 ), demonstrou que ocorreram 33 positivos verdadeiros (sensitividade), 4 positivos falsos, 0 negativos verdadeiros (especificidade) e 2 negativos falsos, no período de 2009. Em 2010 foram 5 positivos verdadeiros, 26 positivos falsos, 2 negativos verdadeiros e 2 negativos falsos. Entre 2013 e 2014 não ocorreu captura de urediniósporos e a avaliação do modelo foi de 0 positivos verdadeiros, 53 positivos falsos, 49 negativos verdadeiros e 0 negativos falsos.

Percebe-se diante da avaliação do modelo com os dados de 2009, que as condições foram muito favoráveis como demonstrado pelo alto número de positivos verdadeiros, zero de negativo verdadeiro, além da alta concentração de inóculo no ar. Em 2010, por outro lado, as condições foram medianamente favoráveis conforme as variáveis do modelo e da captura de inóculos, onde os registros de probabilidade foram mais flutuantes que os de 2009. Deste modo, em 2010 os valores de positivos falsos foram altos, pois apesar da ocorrência de dispersão do patógeno os números de inóculos capturados foram inferiores a 53 urediniósporos $/ \mathrm{cm}^{2}$, isto é, $1 \%$ da CMO considerado no modelo. No período entre 2013 e 2014, as condições não foram favoráveis à ocorrência da ferrugem da videira e nenhum inóculo foi detectado na armadilha. Assim, os registros de saídas das probabilidades do modelo, também foram flutuantes e a maioria inferior ao valor $47 \%$. Diferentemente dos dados de outros anos, 49 negativos verdadeiros foram registrados, número próximo ao de positivos falsos. Como era de se esperar nenhum positivo verdadeiro e negativo falso ocorreu, uma vez que não se constatou dispersão de inóculo.

O resultado obtido com os dados entre 2013 e 2014, demonstra a necessidade de moderação no uso do modelo, pois os parâmetros foram ajustados para predizer a condição para dispersão. Assim, a condição de ambiente pode ser favorável para dispersão, entretanto, desfavorável à infecção do patógeno uma vez que no modelo não foi ajustado precipitação e umidade relativa, dois parâmetros importantes para infecção. Portanto, a utilização conjunta do modelo com técnicas para monitoramento de doença (7) é uma alternativa. Neste caso, a inspeção da ocorrência de ferrugem no campo pode prevenir a tomada de decisão de aplicar um determinado fungicida, devido aos positivos falsos gerados pelo modelo, quando as condições são favoráveis a dispersão do inóculo, mas não há registro da ocorrência da doença no campo.

O uso de modelos de previsão para a ferrugem da videira, doenças policíclicas e destrutivas, pode melhorar a eficiência no manejo ao evitar o uso desnecessário e indiscriminado de agrotóxicos, uma vez que dados de órgão oficial do governo demonstram que a videira carrega bastantes produtos tóxicos (1). O modelo logístico, fundamentado em probabilidade, tem como vantagem à estimativa numérica e pontual de outros modelos, tornar flexível a tomada de decisão por ser facilmente traduzido em riscos ao tratar a tomada de decisão em probabilidades.

Pode-se reduzir o uso de fungicidas ao programar à safra da videira para épocas do ano com temperaturas mais altas e desfavoráveis a doença (17) quando a presença do inóculo for baixa ou zero. No estudo, observou-se que os meses com zero ou rara ocorrência de dispersão de inóculos de P. euvitis foram setembro, outubro, novembro, janeiro, fevereiro e março (Figuras 1 e 3), indicando maior cautela no uso de fungicidas nessa época do ano.

Abril, maio, junho, julho e agosto foram os meses que apresentaram maior concentração de urediniósporos no ar, enquanto os meses entre setembro e março a dispersão de urediniósporos é rara ou zero. A velocidade do vento e a temperatura média diária do ar influenciaram na dispersão de $P$. euvitis e o modelo de regressão logística, baseado nesses parâmetros, auxilia na estimativa do risco de dispersão do patógeno em pomares de videira. Assim, em período de menor disponibilidade de inóculo, seja possível reduzir custos de produção ao não realizar aplicações desnecessárias de fungicidas ou orientar a safra da cultura para épocas com menos riscos de epidemias.

\section{REFERÊNCIAS}

1. Agência Nacional de Vigilância Sanitária. Programa de análise de resíduos de agrotóxicos em alimentos (PARA) - Relatório das amostras analisadas no período de 2017-2018. Brasília: ANVISA, 2019. Disponível em: < http://portal.anvisa.gov.br/programa-de-analise-de-registro-de-agrotoxicos-para> Acesso em 01 de Jul. 2020.

2. Angelotti, F.; Scapin, C.R.; Tessmann, D.J.; Vida, J.B.; Vieira, R.A.; Souto, E.R. Resistência de genótipos de videira à ferrugem. Pesquisa Agropecuária Brasileira, Brasília, DF, v.43, n.9, p.1129-1134, 2008.

3. Angelotti, F.; Tessmann, D.J.; Scapin, C.R.; Vida, J.B. Efeito da temperatura e da luz na germinação de urediniósporos de Phakopsora euvitis. Summa Phytopathologica, Botucatu, v.37, n.1, p.59-61, 2011.

4. Aylor, D.E. The role of intermittent wind in the dispersal of fungal pathogens. Annual Review of Phytopathology, Palo Alto, v.28, p.73-92, 1990.

5. Batista, D.C.; Barbosa, M.A.G.; Moura, M.S.B.; Anjos, J.B. Dinâmica de inóculos e doenças em videira sob sistema convencional e protegido. Revista Caatinga, Mossoró, v.28, n.2, p.256-262, 2015.

6. Bayer, T.M.; Costa, I.F.D. Ocorrência de Phakopsora euvitis Ono em Santa Maria, Rio Grande do Sul. Ciência Rural, Santa Maria, v.36, n.4, p.1307-1308, 2006

7. Bock, C.H.; Poole, G.H.; Parker, P.E.; Gottwald, T.R. Plant disease severity estimated visually, by digital photography and image analysis, and by hyperspectral imaging. Critical Reviews in Plant Sciences, Philadelphia, v.29, n.2, p.59-107, 2010.

8. Calonec, A.; Cartolaro, P.; Chadoeuf, J. Highlighting features of spatiotemporal spread of powdery mildew epidemics in the vineyard using statistical modeling on field experimental data. Phytopathology, Saint Paul, v.99, n.4, p.411-422, 2009.

9. Chatasiri, S.; Ono, Y. Phylogeny and taxonomy of the Asian grapevine leaf rust fungus, Phakopsora euvitis, and its allies (Uredinales). Mycoscience, Tokyo, v.49, n.1, p.66-74, 2008.

10. Gent, D.H.; Wolf, E.; Pethybridge, S.J. Perceptions of risk, risk Aversion, and barriers to adoption of decision support systems and integrated pest management: An introduction. Phytopathology, Saint Paul, v.101, n.6, p.640-643, 2011.

11. Gomes, E.C.S.; Nascimento, L.C.; Perez, J.O.; Leite, R.P.; Silva, F.J.A. Métodos de inoculação de Phakopsora euvitis Ono em Vitis labrusca L. Ciência Rural, Santa Maria, v.40, n.4, p.983-985, 2010.

12. Henderson, D.; Williams, C.J.; Miller, J.S. Forecasting late blight in potato crops of southern Idaho using logistic regression analysis. Plant Disease, Saint Paul, v.91, n.8, p.951-956, 2007. 
13. Hennessy, C.R.; Daly, A.M.; Hearnden, M.N. Assessment of grapevine cultivars for resistance to Phakopsora euvitis. Australasian Plant Pathology, Collingwood, v.36, n.4, p.313-317, 2007.

14. Instituto Brasileiro de Geografia e Estatística. Levantamento Sistemático da Produção Agrícola (LSPA) - novembro 2018. Rio de Janeiro: IBGE, 2018. Disponível em: < https://sidra.ibge.gov.br/home/lspa/brasil>. Acesso em: 13 dez. 2018.

15. Johnson, D.A.; Dung, J.K.S.; Cummings, T.F.; Schroeder, B.K. Development and suppression of aerial stem rot in commercial potato fields. Plant Disease, Saint Paul, v.95, n.3, p.285-291, 2011.

16. Lee, E.T.; Wang, J.W. Statistical methods for survival data analysis. 3rd ed. New York: Wiley, 2003. 521p.

17. Naruzawa, E.S.; Celoto, M.I.B.; Papa, M.F.S.; Tomquelski, G.V.; Boliani, A.C. Estudos epidemiológicos e controle químico de Phakopsora euvitis. Fitopatologia Brasileira, Brasília, v.31, n.1, p.41-45, 2006.

18. Njoroge, S.M.C.; Vallad, G.E.; Park, S.Y.; Kang, S.; Koike, S.T.; Bolda, M.; Burman, P.; Polonik, W.; Subbarao, K.V. Phenological and phytochemical changes correlate with differential interactions of Verticillium dahliae with broccoli and cauliflower. Phytopathology, Saint Paul, v.101, n.5, p.523-534, 2011.
19. Ojiambo, P.S.; Yuen, J.; Van Den Bosch, F.; Madden, L.V. Epidemiology: past, present, and future impacts on understanding disease dynamics and improving plant disease management-a summary of focus issue articles. Phytopathology, Saint Paul, v.107, n.10, p.1092-1094, 2017.

20. Payne, A.F.; Smith, D.L. Development and evaluation of two pecan scab prediction models. Plant Disease, Saint Paul, v.96, n.1, p.117-123, 2012.

21. Pfeufer, E.E.; Ngugi, H.K. Orchard factors associated with resistance and cross resistance to sterol demethylation inhibitor fungicides in populations of Venturia inaequalis from Pennsylvania. Phytopathology, Saint Paul, v.102, n.3, p.272-282, 2012.

22. Teixeira, A.H.C. Informações agrometeorológicas do Polo Petrolina, PE/Juazeiro, BA-1963 a 2009. Petrolina: Embrapa Semiárido, 2010. 21p. (Documentos, 233). Disponível em: <https://ainfo.cnptia.embrapa. br/digital/bitstream/item/31579/1/SDC233.pdf>. Acesso em: 15 fev. 2019

23. Xavier, A.A.; Dariva, F.M.; Ribeiro, R.C.; Mizobutsi, E.H. Ocorrência da ferrugem da videira em Minas Gerais. Revista Brasileira de Fruticultura, Jaboticabal, v.34, n.1, p.317-319, 2012.

24. Wen, L.C; Bowen, C.R.; Hartman, G.L. Prediction of short-distance aerial movement of Phakopsora pachyrhizi urediniospores using machine learning. Phytopathology, Saint Paul, v.107, n.10, p.1187-1198, 2017. 